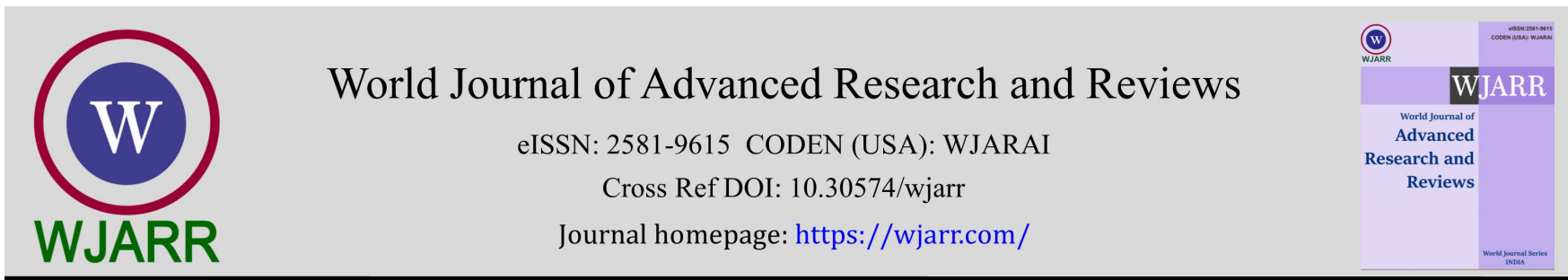

(RESEARCH ARTICLE)

\title{
Determination of sources, spatial variability, and concentration of polycyclic aromatic hydrocarbons in surface water and sediment of Imiringi River
}

\author{
Timi Tarawou ${ }^{1}$, Young Erepamowei ${ }^{1}$ and Ayobami Aigberua ${ }^{2, *}$ \\ ${ }^{1}$ Department of Chemical Sciences, Faculty of Science, Niger Delta University, Wilberforce Island, PMB 71, Yenagoa, \\ Bayelsa State. \\ 2 Department of Environment, Research and Development, Analytical Concept Ltd, Elelenwo, Port Harcourt, Rivers State.
}

World Journal of Advanced Research and Reviews, 2021, 09(03), 309-318

Publication history: Received on 20 February 2021; revised on 23 March 2021; accepted on 25 March 2021

Article DOI: https://doi.org/10.30574/wjarr.2021.9.3.0121

\begin{abstract}
Polycyclic aromatic hydrocarbons (PAHs) are very toxic and persistent environmental micro-contaminants that possess health-impacting tendencies. Environmental levels of PAHs are mainly exacerbated by anthropogenic activities. At elevated concentrations, PAHs become toxic and readily bio-magnify across the food chain. This study was undertaken to determine the concentration and identify possible sources of PAHs in Imiringi River. PAH concentrations depicted the following ranges; Oswan-1 (0.00046 - 0.05010 mg/L and $0.00002-0.01812 \mathrm{mg} / \mathrm{kg}) ; 0$ lem-1 (0.02428 - 2.86264 $\mathrm{mg} / \mathrm{L}$ and $0.00151-3.96536 \mathrm{mg} / \mathrm{kg}$ ); Oswan-4 (0.00041 - $0.30012 \mathrm{mg} / \mathrm{L}$ and $0.00143-0.04530 \mathrm{mg} / \mathrm{kg}$ ) for water and sediment samples respectively. PAHs mostly exceeded the recommended maximum contaminant levels (MCL) stipulated by United States Environmental Protection Agency (USEPA), while high molecular weight PAHs (4 - 6 ring PAHs) are prevalent in the environment. The applied diagnostic ratio (fluoranthene/pyrene) values for surface waters at Oswan-1 (0.8364) and Olem-1 (0.7337), and sediment at 0lem-1 (0.4894) were less than 1, thereby reflecting petrogenic PAHs (from gasoline and diesel). On the other hand, Fluoranthene/Pyrene ratio of sediments from Oswan-1 (2.4558), Oswan-4 (2.3565) and surface water at Oswan-4 (2.0252) depicted values greater than 1, indicating pyrogenic PAHs (from coal combustion). Results further showed Fluoranthene/(Fluoranthene + Pyrene) ratio for all sampling locations at values greater than 0.4 for both surface water and sediment. Hence, revealing pyrogenic source PAHs (from combustion of fossil fuel, coal, grass, wood, etc). Overall, the water body showed reasonable hydrocarbon contamination. As such, it is unsuitable for consumption, as well as recreational and agricultural activities. The application of One-way ANOVA statistics showed spatial variability $(\mathrm{p}<0.05)$ for different PAH species across different sections of river, while principal component analysis (PCA) revealed discrete similarities for most PAHs, excluding anthracene and Dibenz(a,h)anthracene.
\end{abstract}

Keywords: Polycyclic aromatic hydrocarbons; Surface water; Sediments; Imiringi River; pyrogenic; Petrogenic

\section{Introduction}

The Polycyclic Aromatic Hydrocarbons (PAHs) have been extensively studied to understand their distribution, fate and effects in the environment [1]. The PAHs are of special interest because of their carcinogenicity, mutagenicity and teratogenicity. This is because their significant importance lies on the awareness of the biochemical and toxicological roles they play in humans and animals $[2,3]$.

Because of their sources, they are wide spread in the environment. Depending on their volatility, PAHs may be transported far from their original source, ending up in various environmental compartments. Although, their main environmental sink is the organic fraction of soils and sediments $[4,5,6]$.

\footnotetext{
* Corresponding author: Ayobami Aigberua

Department of Environment, Research and Development, Analytical Concept Ltd, Elelenwo, Port Harcourt, Rivers State. 
PAHs are naturally hydrophobic, lipophilic and exhibit great tendency of adsorption to suspended particulates in the aquatic system. Hence, PAHs are majorly deposited in river or seabed sediments [6, 7]. This in turn accumulates to levels high enough to exacerbate toxic effects within the environment $[8,9]$. PAHs are also bio available to aquatic animals and consequently find their way into dietary sources $[3,10,11]$. They are assumed to have potentials for endocrine system disruption $[12,13,14]$ and are also listed as priority organic pollutants with their photo-oxidation products and alkylated derivatives on account of their tendency to be carcinogenic, teratogenic and mutagenic $[10,13,14]$.

These aromatic compounds (PAHs) are naturally present in fossil fuels and find their way into the environment as byproducts of incomplete combustion of organic materials (oil and gas, coal, biomass, firewood, garbage, tobacco or charbroiled meat), by way of incineration, vehicular exhaust emissions, oil exploration, power generation and various industrial production practices $[15,16]$. Abdel-Shafy [17] observed that PAHs are emitted into the atmosphere and other receiving environmental compartments mainly via the processing of crude petroleum (refining of crude oil and synthetic fuels), use of fossil fuels (thermal power generation, domestic heating and burning of organic wastes at unregulated dumpsites, vehicle exhaust emissions) and fallouts (wild/forest fires and volcanic activities). Larger quantity of these compounds arrive the marine environments from coastal regions as urban run-off, domestic wastes, river run-off, industrial discharges and emissions from engine and bilge pumping. Other times, they infiltrate the aquatic bodies in the form of leachates from bulwarks and docksides [16].

There are two Sources of PAHs in the environment, namely; Pyrogenic and Petrogenic sources [4]. Pyrogenic PAHs are formed whenever organic substances are exposed to high temperatures under low oxygen or no oxygen conditions. As such, the destructive distillation of coal into coke and coal tar, or the thermal cracking of petroleum residuals into lighter hydrocarbons results in intentionally occurring pyrolytic PAHs. Meanwhile, other unintentional processes occur during the incomplete combustion of motor fuels in cars and trucks, the incomplete combustion of wood in forest fires and fireplaces, and the incomplete combustion of fuel oils in heating systems [18]. PAHs formed during crude oil maturation and similar processes are called Petrogenic [19]. Such Petrogenic PAHs are common due to the widespread transportation, storage, and use of crude oil and crude oil products. Some of the major sources of Petrogenic PAHs include oceanic and freshwater oil spills, underground and above ground storage tank leaks, and the accumulation of vast numbers of small releases of gasoline, motor oil, and related substances associated with transportation.

The aim of this study is to determine the sources, spatial distribution, and compare the concentration levels of polycyclic aromatic hydrocarbons in the Imiringi River, whilst assessing the status of the environment with respect to stipulated United States Environmental Protection Agency (USEPA) regulatory guidelines.

To achieve the above aim, the following objectives were set thus; to quantify the levels of PAHs in sediments and water samples of Imiringi River at different sampling points, as well as decipher the sources of PAHs by calculating the (Fluoranthene/pyrene), and (Fluoranthene/Fluoranthene + pyrene) ratios. Finally, the study is aimed at assessing environmental compliance viz: USEPA maximum contaminant level (MCL) of PAHs.

\section{Material and methods}

\subsection{Equipment Specification}

HP 6890 series gas chromatograph coupled with an HP 5973 mass selective detector (MSD) was used for the analysis. The capillary column used for separation of PAH components is the DB- 5 type (30 m length x 0.32 internal diameter wide-bore). This column is lined with a stationary phase material (95\% dimethyl - 5\% phenyl polysiloxane). Also, the carrier gas utilized for this test is $99.999 \%$ helium.

\subsection{Reagents}

The following reagents were utilized during sample extraction: Dichloromethane (BDH Chemicals Ltd, Poole-England), n-hexane (BDH Chemicals Ltd, Poole-England), activated silica (Burgoyne Burbidges \& Co. Reagents, Mumbai, India), anhydrous sodium sulphate (SureChem Products Ltd, Suffolk, England).

\subsection{Study Area}

The study was carried out along the Imiringi River stretch, which is located in Imiringi town, Ogbia Local Government Area of Bayelsa State. This water channel runs across the entire length of Imiringi community. For the purpose of this study, three sampling points were geo-referenced along the river course (Oswan-1, Olem-1 and 0swan-4) (Table 1). 
Table 1 Geographical coordinates of field sampling points.

\begin{tabular}{|l|l|l|}
\hline SITE & LATITUDE & LONGITUDE \\
\hline Oswan-1 & $4.8543^{\prime} \mathrm{N} 2.3786^{\prime \prime} \mathrm{E}$ & $6.3723^{\prime} \mathrm{N} 3.1862^{\prime \prime} \mathrm{E}$ \\
\hline Olem-1 & $4.5543^{\prime} \mathrm{N} 2.4186^{\prime \prime} \mathrm{E}$ & $6.4023^{\prime} \mathrm{N} 2.1862^{\prime \prime} \mathrm{E}$ \\
\hline Oswan-4 & $4.3543^{\prime} \mathrm{N}$ 7.5107” E & $6.4532^{\prime}$ N 5.4903” E \\
\hline
\end{tabular}

\subsection{Sample Collection}

Sampling was done on the 30th of August, 2019 at Oswan-1, Olem-1 and Oswan-4 sections of the Imiringi River. Surface water samples were collected and transferred into $250 \mathrm{~mL}$ transparent glass bottles with glass corks. A grab sampler was deployed to acquire seabed sediments from each geo-referenced sampling point and transferred into Ziploc bags. With a masking tape, all sampling containers were distinctly labeled. Afterwards, water samples were fixed with sulphuric acid $\left(\mathrm{H}_{2} \mathrm{SO}_{4}\right)$. Meanwhile, all samples were stored in a cool box containing ice packs, before being immediately transported to the laboratory for sample pre-treatment and analysis.

\subsection{PAH extraction and clean up}

For each water sample, exactly $250 \mathrm{~mL}$ of was extracted with $25 \mathrm{~mL}$ of dichloromethane/n-hexane solvent (1:3 v/v) in a separating funnel. The aqueous phase was collected and extraction was carried out with a second aliquot of dichloromethane/n-hexane solvent $(25 \mathrm{~mL}$ ) in order to improve the percentage recovery of extraction (procedure is as extensively described in USEPA Method 3510C [20].

On the other hand, $1 \mathrm{~g}$ of air-dried and homogenized sediment sample was extracted via sonication, using duplicate 15 $\mathrm{mL}$ aliquots of dichloromethane/n-hexane solvent $(1: 3 \mathrm{v} / \mathrm{v})$ [7]. The respective extracts from the different sample matrices were then evaporated to $1 \mathrm{~mL}$ using a temperature regulated water bath at $40^{\circ} \mathrm{C}$. The concentrated extracts were cleansed by solid phase extraction method. Afterwards, $1 \mu \mathrm{L}$ portion of the cleansed extract was injected into the GC-MSD.

\subsection{GC-MSD Analysis}

Following the extraction of PAHs from water and sediment samples, $1 \mu \mathrm{L}$ of the reconstituted sample extract was injected into the gas chromatograph - mass selective detector (GC-MSD). Separation of each PAH fraction is known to separate as the vapour constituent partitions between the mobile (helium) and stationary ( $95 \%$ dimethyl - 5\% phenyl polysiloxane) phases. In order to obtain optimum resolution of the calibrated PAH components, the following equipment conditions (starting oven temperature $=65^{\circ} \mathrm{C}$, final oven temperature $=320{ }^{\circ} \mathrm{C}$, detector temperature $=$ $310^{\circ} \mathrm{C}$, injector temperature $=275^{\circ} \mathrm{C}$, helium flow rate $=30 \mathrm{~mL} / \mathrm{min}$.

\subsection{Diagnostic Ratios/Delineation of PAH}

The two (2) diagnostic ratios that were applied for this source apportionment include: Fluoranthene/Pyrene (Flu/Py) ratio, and the Fluoranthene/(Fluoranthene + Pyrene) (Flu/(Flu + Py) ratio.

\subsection{Statistical Analysis of Data/Spatial Variability}

One-way ANOVA and principal component analysis were used to study variabilities of PAHs in the different sites and among PAHs. SPSS statistical package (Windows version 18) and software Excel 2007 were used for data analysis.

\section{Results and discussion}

\subsection{PAH Distribution}

The concentration of PAH components identified in surface water and sediment samples from three (3) site locations (Oswan-1, Olem-1 and Oswan-4) of Imiringi River are presented in Tables 2 and 3. For the surface water samples, naphthalene, acenaphthene, acenaphthylene, fluorene were not detected in all samples, while phenanthrene was not detected in Olem 1 and Oswan 4. Meanwhile, anthracene was not detected in Olem 1. On the other hand, sediment samples were void of naphthalene, acenaphthene, acenaphthylene components in Olem 1 and Oswan 4 locations, while fluorene was not detected in Olem 1. 
Table 2 Concentration of PAHs in Imiringi water.

\begin{tabular}{|l|l|l|l|}
\hline PAH fractions & Oswan-1 & Olem-1 & Oswan-4 \\
\hline Naphthalene & $0.00 \mathrm{E}+00 \pm 0.00 \mathrm{E}+00$ & $0.00 \mathrm{E}+00 \pm 0.00 \mathrm{E}+00$ & $0.00 \mathrm{E}+00 \pm 0.00 \mathrm{E}+00$ \\
\hline Acenaphthene & $0.00 \mathrm{E}+00 \pm 0.00 \mathrm{E}+00$ & $0.00 \mathrm{E}+00 \pm 0.00 \mathrm{E}+00$ & $0.00 \mathrm{E}+00 \pm 0.00 \mathrm{E}+00$ \\
\hline Acenaphthylene & $0.00 \mathrm{E}+00 \pm 0.00 \mathrm{E}+00$ & $0.00 \mathrm{E}+00 \pm 0.00 \mathrm{E}+00$ & $0.00 \mathrm{E}+00 \pm 0.00 \mathrm{E}+00$ \\
\hline Fluorene & $0.00 \mathrm{E}+00 \pm 0.00 \mathrm{E}+00$ & $0.00 \mathrm{E}+00 \pm 0.00 \mathrm{E}+00$ & $0.00 \mathrm{E}+00 \pm 0.00 \mathrm{E}+00$ \\
\hline Phenanthrene & $7.17 \mathrm{E}-04^{\mathrm{b}} \pm 6.03 \mathrm{E}-05$ & $0.00 \mathrm{E}+00^{\mathrm{a}} \pm 0.00 \mathrm{E}+00$ & $0.00 \mathrm{E}+00^{\mathrm{a}} \pm 0.00 \mathrm{E}+00$ \\
\hline Anthracene & $1.38 \mathrm{E}-03^{\mathrm{a}} \pm 8.02 \mathrm{E}-05$ & $0.00 \mathrm{E}+00^{\mathrm{a}} \pm 0.00 \mathrm{E}+00$ & $2.99 \mathrm{E}-01^{\mathrm{b}} \pm 3.22 \mathrm{E}-03$ \\
\hline Fluoranthene & $4.40 \mathrm{E}-04^{\mathrm{a}} \pm 2.00 \mathrm{E}-05$ & $9.01 \mathrm{E}-02^{\mathrm{c}} \pm 2.65 \mathrm{E}-04$ & $3.22 \mathrm{E}-03^{\mathrm{b}} \pm 1.15 \mathrm{E}-04$ \\
\hline Pyrene & $5.43 \mathrm{E}-04^{\mathrm{a}} \pm 3.06 \mathrm{E}-05$ & $1.23 \mathrm{E}-01^{\mathrm{c}} \pm 7.32 \mathrm{E}-04$ & $1.59 \mathrm{E}-03^{\mathrm{b}} \pm 6.00 \mathrm{E}-05$ \\
\hline Benz(a)anthracene & $4.25 \mathrm{E}-03^{\mathrm{a}} \pm 2.90 \mathrm{E}-04$ & $1.10 \mathrm{E}+00^{\mathrm{b}} \pm 2.14 \mathrm{E}-02$ & $1.09 \mathrm{E}-02^{\mathrm{a}} \pm 2.43 \mathrm{E}-04$ \\
\hline Chrysene & $8.50 \mathrm{E}-04^{\mathrm{b}} \pm 5.00 \mathrm{E}-05$ & $3.28 \mathrm{E}-02^{\mathrm{c}} \pm 1.70 \mathrm{E}-04$ & $4.17 \mathrm{E}-04^{\mathrm{a}} \pm 3.06 \mathrm{E}-05$ \\
\hline Benzo(b)fluoranthene & $5.07 \mathrm{E}-02^{\mathrm{c}} \pm 4.96 \mathrm{E}-04$ & $3.27 \mathrm{E}-02^{\mathrm{b}} \pm 1.32 \mathrm{E}-04$ & $1.34 \mathrm{E}-02^{\mathrm{a}} \pm 9.54 \mathrm{E}-05$ \\
\hline Benzo(k)Fluoranthene & $8.70 \mathrm{E}-04^{\mathrm{a}} \pm 3.00 \mathrm{E}-05$ & $2.43 \mathrm{E}-02^{\mathrm{c}} \pm 7.51 \mathrm{E}-05$ & $1.55 \mathrm{E}-03^{\mathrm{b}} \pm 7.77 \mathrm{E}-05$ \\
\hline Indeno(1,2,3-cd)pyrene & $4.24 \mathrm{E}-03^{\mathrm{b}} \pm 1.00 \mathrm{E}-04$ & $4.09 \mathrm{E}-02^{\mathrm{c}} \pm 1.75 \mathrm{E}-04$ & $2.74 \mathrm{E}-03^{\mathrm{a}} \pm 1.01 \mathrm{E}-04$ \\
\hline Dibenz(a,h)anthracene & $2.07 \mathrm{E}-02^{\mathrm{a}} \pm 3.86 \mathrm{E}-04$ & $2.96 \mathrm{E}+00^{\mathrm{b}} \pm 1.25 \mathrm{E}-01$ & $8.91 \mathrm{E}-02^{\mathrm{a}} \pm 3.58 \mathrm{E}-04$ \\
\hline
\end{tabular}

PAH concentrations ranged from $(0.00 \mathrm{E}+00$ to $5.07 \mathrm{E}-02 \mathrm{mg} / \mathrm{L}),(0.00 \mathrm{E}+00$ to $2.96 \mathrm{E}+00 \mathrm{mg} / \mathrm{L})$, and $(0.00 \mathrm{E}+00$ to $2.99 \mathrm{E}-$ $01 \mathrm{mg} / \mathrm{L}$ ) for Oswan-1, Olem-1 and Oswan-4 surface water samples respectively. Most noticeably, the readily volatile light molecular weight polycyclic aromatic hydrocarbons (LPAHs) (Naphthalene, Acenaphthene, Acenaphthylene, and Fluorene) were found below measurable detection limit (MDL) in water samples. These fractions may have been lost due to environmental attenuation factors such as elevated temperature, low humidity, and tidal nature of the river, amongst others. Aigberua [21] had reported loss in light molecular weight PAHs in surface waters of the Imiringi River.

In addition, Table 2 depicted a total of 10, 8 and 9 PAH species in the water samples collected from 0swan-1 Olem-1 and Oswan-4 field locations respectively. The higher number of PAH species observed at Oswan locations may be due to its upstream position, which leads to the redistribution of contaminants towards downstream zones at Olem-1. Generally, high molecular weight fractions (HPAHs) are the most important species observed in the environment. Hence, the identified PAHs, Benzo(b)fluoranthene depicted the highest concentration with a value of $0.05010 \mathrm{mg} / \mathrm{L}$, while Fluoranthene recorded the lowest concentration with a value of $0.00046 \mathrm{mg} / \mathrm{L}$ at Oswan-1 sample station. Meanwhile, the Olem-1 sample site depicted Dibenz(a,h)anthracene (2.86264 mg/L) with the most concentration and Benzo(k)fluoranthene with the least concentration $(0.02428 \mathrm{mg} / \mathrm{L})$. Also, the Oswan-4 sample site depicted anthracene $(0.30012 \mathrm{mg} / \mathrm{L})$ with the highest concentration, while chrysene $(0.00041 \mathrm{mg} / \mathrm{L})$ reflected the least concentration. In the same vein, Aigberua [21] had recorded relatively higher concentrations of high molecular weight PAH fractions.

Overall, the downriver location (Olem-1) is most contaminated with PAHs. Most importantly, all identified PAHs were observed at concentrations exceeding the maximum allowable concentration ( $0.0002 \mathrm{mg} / \mathrm{L})$ as given by Agency for Toxic Substance and Disease Regulation (ATSDR). The concentrations of fourteen (14) PAH components were similarly identified in sediment samples from three (3) site locations (Oswan-1, Olem-1 and Oswan-4) of Imiringi river (Table 3). 
Table 3 Concentration of PAHs in Imiringi sediment.

\begin{tabular}{|l|l|l|l|}
\hline PAH fractions & Oswan-1 & Olem-1 & Oswan-4 \\
\hline Naphthalene & $2.33 \mathrm{E}-05^{\mathrm{b}} \pm 5.77 \mathrm{E}-06$ & $0.00 \mathrm{E}+00^{\mathrm{a}} \pm 0.00 \mathrm{E}+00$ & $0.00 \mathrm{E}+00^{\mathrm{a}} \pm 0.00 \mathrm{E}+00$ \\
\hline Acenaphthene & $7.50 \mathrm{E}-04^{\mathrm{b}} \pm 9.17 \mathrm{E}-05$ & $0.00 \mathrm{E}+00^{\mathrm{a}} \pm 0.00 \mathrm{E}+00$ & $0.00 \mathrm{E}+00^{\mathrm{a}} \pm 0.00 \mathrm{E}+00$ \\
\hline Acenaphthylene & $1.15 \mathrm{E}-03^{\mathrm{b}} \pm 9.71 \mathrm{E}-05$ & $0.00 \mathrm{E}+00^{\mathrm{a}} \pm 0.00 \mathrm{E}+00$ & $0.00 \mathrm{E}+00^{\mathrm{a}} \pm 0.00 \mathrm{E}+00$ \\
\hline Fluorene & $3.97 \mathrm{E}-03^{\mathrm{c}} \pm 9.61 \mathrm{E}-05$ & $0.00 \mathrm{E}+00^{\mathrm{a}} \pm 0.00 \mathrm{E}+00$ & $2.56 \mathrm{E}-03^{\mathrm{b}} \pm 2.40 \mathrm{E}-04$ \\
\hline Phenanthrene & $2.17 \mathrm{E}-02^{\mathrm{b}} \pm 1.76 \mathrm{E}-04$ & $1.52 \mathrm{E}-0{ }^{\mathrm{a}} \pm 6.56 \mathrm{E}-05$ & $1.70 \mathrm{E}-03^{\mathrm{a}} \pm 2.52 \mathrm{E}-05$ \\
\hline Anthracene & $4.97 \mathrm{E}-03^{\mathrm{a}} \pm 1.50 \mathrm{E}-04$ & $2.18 \mathrm{E}-0^{\mathrm{b}} \pm 2.20 \mathrm{E}-04$ & $2.53 \mathrm{E}-02^{\mathrm{c}} \pm 2.63 \mathrm{E}-04$ \\
\hline Fluoranthene & $6.93 \mathrm{E}-03^{\mathrm{b}} \pm 1.81 \mathrm{E}-04$ & $3.38 \mathrm{E}-02^{\mathrm{c}} \pm 2.28 \mathrm{E}-04$ & $5.35 \mathrm{E}-03^{\mathrm{a}} \pm 8.33 \mathrm{E}-05$ \\
\hline Pyrene & $2.92 \mathrm{E}-00^{\mathrm{b}} \pm 9.54 \mathrm{E}-05$ & $6.87 \mathrm{E}-02^{\mathrm{c}} \pm 1.90 \mathrm{E}-04$ & $2.42 \mathrm{E}-03^{\mathrm{a}} \pm 1.11 \mathrm{E}-04$ \\
\hline Benz(a)anthracene & $8.98 \mathrm{E}-03^{\mathrm{a}} \pm 1.42 \mathrm{E}-04$ & $3.20 \mathrm{E}-01^{2} \pm 1.10 \mathrm{E}-03 \mathrm{c}$ & $1.13 \mathrm{E}-00^{\mathrm{b}} \pm 4.02 \mathrm{E}-04$ \\
\hline Chrysene & $1.40 \mathrm{E}-02^{\mathrm{b}} \pm 1.56 \mathrm{E}-04$ & $2.48 \mathrm{E}-01^{\mathrm{c}} \pm 1.33 \mathrm{E}-03$ & $2.73 \mathrm{E}-03^{\mathrm{a}} \pm 1.25 \mathrm{E}-04$ \\
\hline Benzo(b)fluoranthene & $1.30 \mathrm{E}-02^{\mathrm{a}} \pm 1.55 \mathrm{E}-04$ & $3.97 \mathrm{E}+00^{\mathrm{b}} \pm 8.57 \mathrm{E}-03$ & $4.26 \mathrm{E}-03^{\mathrm{a}} \pm 7.09 \mathrm{E}-05$ \\
\hline Benzo(k)Fluoranthene & $1.46 \mathrm{E}-03^{\mathrm{a}} \pm 1.03 \mathrm{E}-04$ & $6.34 \mathrm{E}-01^{\mathrm{b}} \pm 2.14 \mathrm{E}-03$ & $1.41 \mathrm{E}-03^{\mathrm{a}} \pm 9.17 \mathrm{E}-05$ \\
\hline Indeno(1,2,3-cd)pyrene & $4.25 \mathrm{E}-03^{\mathrm{a}} \pm 1.46 \mathrm{E}-04$ & $4.04 \mathrm{E}-02^{\mathrm{c}} \pm 5.06 \mathrm{E}-04$ & $4.96 \mathrm{E}-03^{\mathrm{b}} \pm 1.04 \mathrm{E}-04$ \\
\hline Dibenz(a,h)anthracene & $2.09 \mathrm{E}-02^{\mathrm{a}} \pm 1.53 \mathrm{E}-04$ & $2.91 \mathrm{E}+00^{\mathrm{b}} \pm 4.54 \mathrm{E}-02$ & $4.50 \mathrm{E}-02^{\mathrm{a}} \pm 2.71 \mathrm{E}-04$ \\
\hline
\end{tabular}

Data is expressed as mean \pm standard deviation; different letters (superscripted on the mean values) across same row indicate significant difference $(\mathrm{p}<0.05)$ according to Waller-Duncan statistics

PAH concentrations ranged from (2.33E-05 to $2.09 \mathrm{E}-02 \mathrm{mg} / \mathrm{kg}),(0.00 \mathrm{E}+00$ to $3.97 \mathrm{E}+00 \mathrm{mg} / \mathrm{kg})$, and $(0.00 \mathrm{E}+00$ to $4.50 \mathrm{E}-02 \mathrm{mg} / \mathrm{kg}$ ) for Oswan-1, Olem-1 and Oswan-4 sediment respectively. Most noticeably, the readily volatile light molecular weight polycyclic aromatic hydrocarbons (LPAHs) Naphthalene, Acenaphthene and Acenaphthylene were observed below measurable detection limit (MDL) across sediment samples of Olem-1 and Oswan-4 locations. The undetected PAH species may have been lost to environmental attenuation factors such as elevated temperature, low humidity, and tidal nature of river, amongst others. Aigberua [21] had reported similar trends for surface waters of Imiringi River.

In addition, Table 3 depicted a total of 14,10 and 11 PAH species in the sediment samples collected from Oswan-1 Olem1 and Oswan-4 field locations respectively. The higher number of PAH species observed at Oswan locations may be due to its upstream location and the effect of redistribution towards the downstream river section at Olem-1. Generally, high molecular weight fractions (HPAHs) are the most important species found in the environment. Hence, Dibenz(a,h)anthracene was observed with the highest concentration at upstream locations of 0swan-1 (2.09E-02 $\mathrm{mg} / \mathrm{kg}$ ) and Oswan-4 (4.50E-02 mg/kg) respectively. On the other hand, Benzo(b)fluoranthene $(3.97 \mathrm{E}+00 \mathrm{mg} / \mathrm{kg}) \mathrm{was}$ the most important PAH fraction at Olem-1 downriver location. Like the surface water trend observed, the downriver sediment location at Olem-1 was recorded as being most contaminated.

Apart from the unidentified PAH compounds, all other observed PAHs had concentrations exceeding the maximum allowable concentration ( $0.0002 \mathrm{mg} / \mathrm{L}$ ) as given by Agency for Toxic Substance and Disease Regulation (ATSDR). Similarly, Aigberua [21] had reported the prevalence of high molecular weight PAHs (4-6 ring PAHs) in surface waters of Imiringi River. In the same vein, Yang et al. [22] had reported the prevalence of 4 to 6 ring PAHs in suspended particulate dust around the Niger Delta region. In contrast, Wu et al. [6] had reported 2 to 4 ring PAHs as the most important fractions of river Chaohu, China, thereby reflecting the predominance of petrogenic PAHs.

The standards for maximum contaminant level (MCL) of PAHs as reported by USEPA (United States Environmental Protection Agency) are provided in Table 6. 
Table 4 Standards and regulations for PAHs in water [23].

\begin{tabular}{|l|l|}
\hline PAH toxicants & Maximum contaminant level (MCL) mg/L \\
\hline Benz(a)anthracene & 0.0001 \\
\hline $\begin{array}{l}\text { Benzo(a)pyrene, } \\
\text { Benzo(b)fluoranthene, } \\
\text { Benzo(k)fluoranthene, Chrysene }\end{array}$ & 0.0002 \\
\hline Dibenz(a,h)anthracene & 0.0003 \\
\hline Indeno(1,2,3-cd)pyrene & 0.0004 \\
\hline
\end{tabular}

Table 6 shows the maximum contaminant level (MCL) reported by USEPA. The comparative evaluation of PAHs obtained from test water sample shows concentrations exceeding USEPA standards. Based on the results obtained from this study (Tables 2 and 3), water from Imiringi River is not suitable for drinking, domestic and recreational purposes. This is owing to the risk of ingestion and biomagnifications across the food chain. Results obtained from this study is similar to the findings of Jack and Abiye [24] where PAH concentrations of the Eleme and Okrika creeks of Niger Delta were reported to exceed USEPA regulatory limits.

There was significant variation $(\mathrm{p}<0.05)$ for Phenanthrene, Chrysene, Benzo(b)fluoranthene, and Indeno(1,2,3-cd pyrene) at Oswan-1 sampling point. Apart from Naphthalene, Acenaphthene, Acenaphthylene, Fluorene, Phenanthrene, and Anthracene in Olem-1 location, all other PAHs were significantly divergent $(\mathrm{P}<0.05)$. Furthermore, only PAH species (Anthracene, Fluoranthene, Pyrene, and Benzo(k)fluoranthene) showed significant difference $(\mathrm{P}<0.05)$ at the Oswan-4 location of Imiringi river (Table 2).

There was significant variation $(\mathrm{p}<0.05)$ for Fluorene, as well as Naphthalene, Acenapthene, Acenaphthylene, Phenanthrene for sediment samples of Oswan-1 location. For Olem-1 location, the most significant variation ( $p<0.05$ ) was observed for two (2) PAH species clusters (Fluoranthene, Pyrene, Benzo(a)anthracene, chrysene, Indeno(1,2,3cd)pyrene) and (Naphthalene, Acenaphthene, Acenaphthylene, Fluorene, pyrene). Also, The least significantly different PAH species $(\mathrm{P}<0.05)$ found in Oswan-4 upriver section were (Fluorene, Benzo(a)anthracene, Indeno(1,2,3-cd)pyrene and (Anthracene) (Table 3).

\subsection{Applied diagnostic ratios and delineation of PAH sources}

From the concentration values presented in Tables 2 and 3 respectively, the source of elevated PAHs can be deduced and likely reasons for exacerbated levels can be predicted. The two (2) diagnostic ratios that were applied for this source apportionment include: Fluoranthene/Pyrene (Flu/Py) ratio, and Fluoranthene/(Fluoranthene + Pyrene) (Flu/(Flu + Py)) ratio as described in Table 4.

Table 5 Diagnostic ratio values and PAH emission sources [25].

\begin{tabular}{|l|l|l|}
\hline Diagnostic Ratio & Petrogenic & Pyrogenic \\
\hline Flu/Py & $<1$ (gasoline, diesel) & $>1$ (coal combustion) \\
\hline Flu/Flu + Py & $<0.4$ (petrol) & $>0.4$ (fossil fuel, grass, wood) \\
\hline
\end{tabular}

Table 5 gives a direction on the sources of distribution of PAHs in the water and sediment samples. The values obtained from the applied ratios are an indication of likely originating sources of PAHs. The diagnostic ratio values for the surface water and sediments of Oswan-1, Olem-1 and Oswan-4 sample points along the Imiringi River are presented in Table 6. 
Table 6 Calculated diagnostic ratio values of test samples.

\begin{tabular}{|l|l|l|l|l|l|l|}
\hline \multirow{2}{*}{ Diagnostic Ratio } & \multicolumn{2}{|c|}{ Oswan-1 } & \multicolumn{2}{c|}{ Olem-1 } & \multicolumn{2}{c|}{ Oswan-4 } \\
\cline { 2 - 7 } & Surface Water & Sediment & Surface Water & Sediment & Surface Water & Sediment \\
\hline Flu/Py & 0.8364 & 2.4558 & 0.7337 & 0.4894 & 2.0252 & 2.3565 \\
\hline Flu/Flu + Py & 0.4554 & 0.7106 & 0.4232 & 0.3286 & 0.6694 & 0.7021 \\
\hline
\end{tabular}

Flu represents Fluoranthene, while Py represents Pyrene

Table 5 indicates that diagnostic ratio Flu/Py for the surface water samples at Oswan-1 (0.8364), Olem-1 (0.7337) and sediment sample at Olem-1 (0.4894) were less than $1(<1)$, thereby depicting petrogenic source of PAHs (gasoline and diesel). This could have emanated from spill-over effects of industrial wastes and oil spillages from nearby oil installations along the river tributary. While the Flu/Py ratio of sediments at Oswan-1 (2.4558), Oswan-4 (2.3565) and surface water at Oswan-4 (2.0252) were observed at concentrations greater than 1 ( $>1)$, indicating a pyrogenic source of PAHs (coal combustion). Results highlighted in Table 5 further revealed most Flu/(Flu + Py) ratios for all sample sites at values greater than $0.4(>0.4)$. This is an indication that the sources of PAHs are pyrogenic (pyrolysis or combustion of Fossil fuel, Grass, wood, among others). This may be due to intensive agricultural practice of bush burning. In addition, the sediment sample at Olem-1 depicted a Flu/(Flu + Py) ratio of less than $0.4(<0.4)$, this being an indication of petrogenic-sourced PAHs (petrol combustion). Similar results were obtained when Zhi, et al. [26] studied the fate of PAHs in water columns from Poyang lake.

\subsection{Statistical Data Analysis for the Identification of Spatial Variability}

Using the principal component analysis multivariate statistical tool, PAH species variability was determined for surface water and sediment across the three river sections. Figures 1 and 2 highlight the associated trend/pattern.

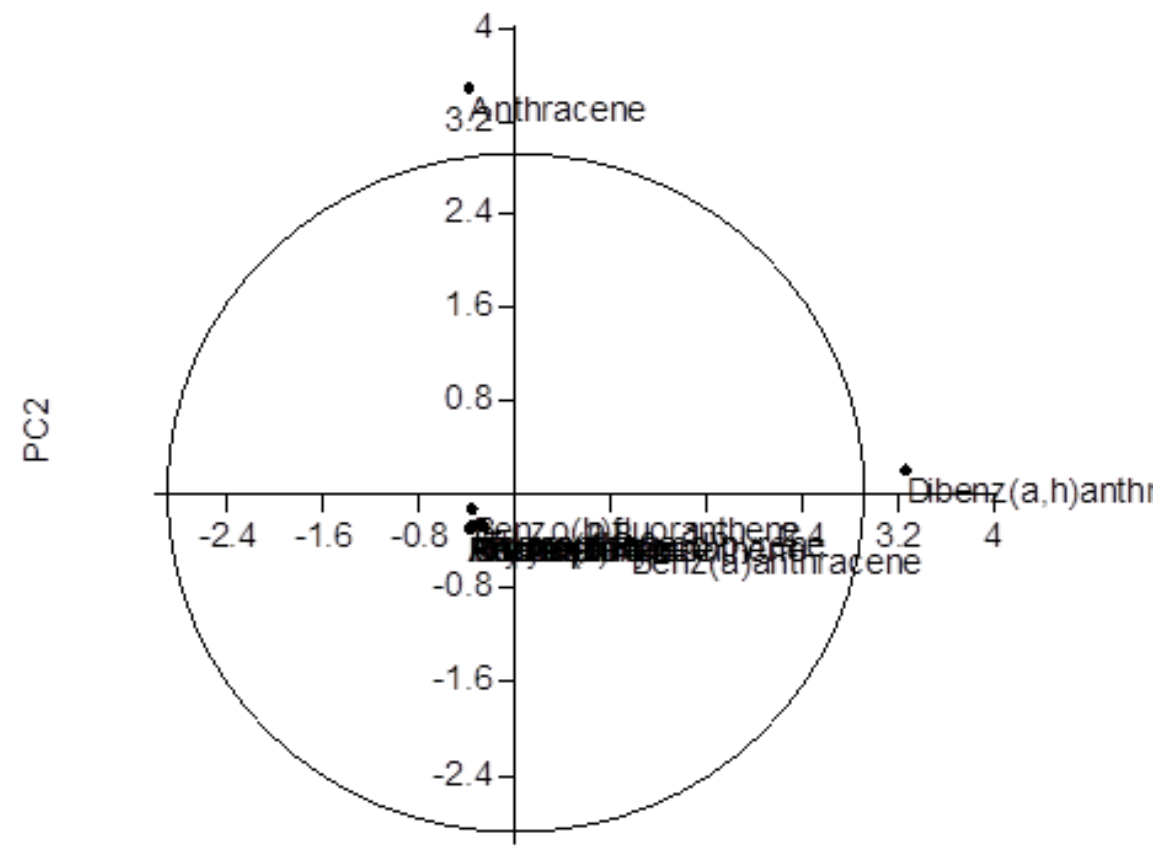

PC1

Figure 1 Principal component analysis of Imiringi water 


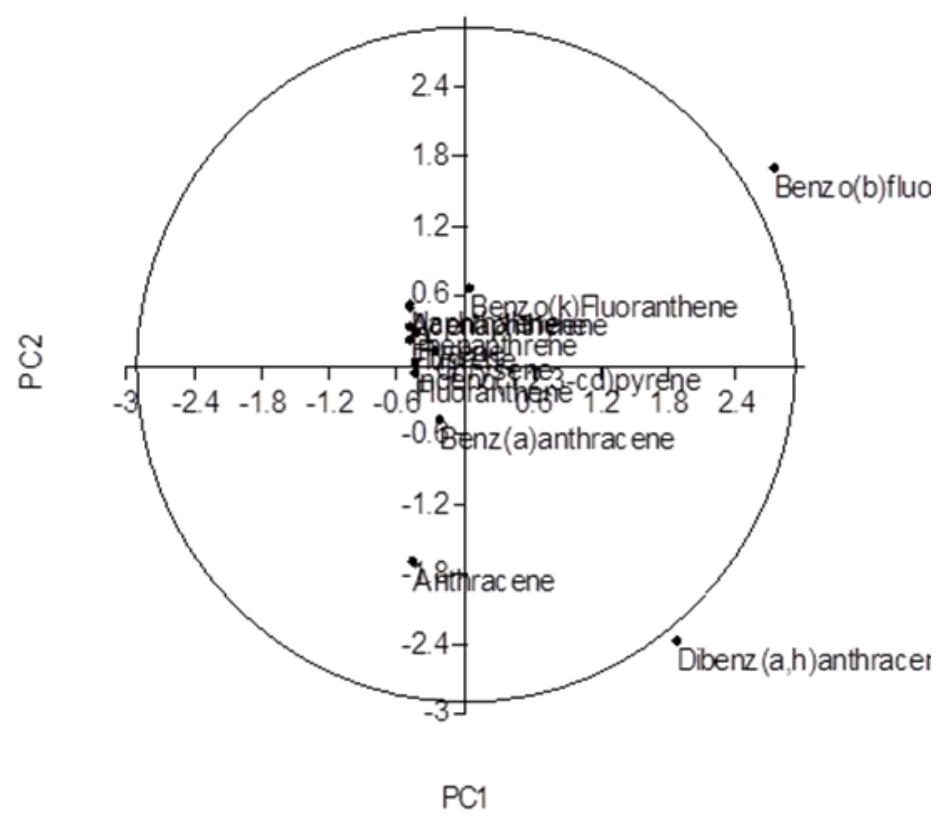

Figure 2 Principal component analysis of Imiringi sediment

Principal component analysis (PCA) revealed twelve (12) of the fourteen (14) PAH species to be discretely located with close similarity in both surface water and sediment samples. However, two PAH fractions each (Anthracene, Dibenz(a,h)anthracene) and (Benzo(b)fluoranthene, Dibenz(a,h)anthracene) showed the most dissimilarity for Imiringi surface water and sediment respectively. For surface water, the spatial variability may have been due to outlier concentrations of Anthracene (Ant) at Oswan-4 upstream and Dibenz(a,h)anthracene at Olem-1 midstream section. The elevated level of LPAH (Anthracene) in surface water, especially within the upriver section (Oswan-4) may have stemmed from oil seepages that stem from illegal bunkering activities and faulty underlying oil pipelines. Conversely, the aggravated concentration of HPAH (Dibenz(a,h)anthracene) at Olem-1 section (downstream) is probably due to open combustion of biomass from waste dumps and bush burning occurrences (Figure 1). Meanwhile, the spatial variability in sediment may have resulted from outlier concentrations of Benzo(b)fluoranthene at downstream location (Olem-1) and Dibenz(a,h)anthracene within upstream locations (Oswan-1 and Oswan-4). In addition, the high level of HPAHs (Benzo(b)fluoranthene and Dibenz(a,h)anthracene) is solely an indication of biomass combustion (Figure 2). A spatial variability trend similar to the current study was reported for surface water samples collected from Imiringi River [21]. Also, due to oil bunkering activities along the Azuabie creek, the affected water ways recorded outlier concentrations of hydrocarbons (TPH and PAHs) as compared to control location. As such, PCA of contaminated water and sediments showed significant variability from the control location [14].

\section{Conclusion}

This study established that PAHs are present in the Imiringi River at significantly diverging concentrations across geospatial sampling points. PAHs depicted concentrations exceeding USEPA recommended contamination levels in water. As such, the Imiringi water body can be considered unsuitable for drinking purposes, or domestic and recreational activities. The PAHs found within the environment are linked to both petrogenic (petrol combustion) and pyrogenic (forest fires, coal combustion and burning of fossil fuel) sources. However, there is a comparatively higher distribution of pyrogenic HPAHs. This may likely be due to the poor volatility of HPAHs.

\section{Compliance with ethical standards}

\section{Acknowledgments}

The authors wish to thank Analytical Concept Limited for their technical support during the laboratory analysis.

\section{Disclosure of conflict of interest}

All authors declare no competing interest. 


\section{References}

[1] Laane RWPM, Sonneveldt HLA, Van der Weyden AJ, Loch JPG, Groeneveld G. Trends in the spatial and temporal distribution of metals $(\mathrm{Cd}, \mathrm{Cu}, \mathrm{Zn}$ and $\mathrm{Pb}$ ) and organic compounds (PCBs and PAHs) in Dutch coastal zone sediments from 1981 to 1996: A model case study for Cd and PCBs. J. Sea Res. 1999; 41(2): 1-17.

[2] Agarwal T. Concentration level, pattern and toxic potential of PAHs in traffic soil of Delhi. India, J. Hazard. Mater. 2009; 171: 894-900.

[3] El Nemr A, El-Sikaily A, Khaled A, Ragab S. Distribution patterns and risk assessment of hydrocarbons in bivalves from Egyptian Mediterranean coast. Blue Biotechnol. J. 2012; 1(3): 457-472.

[4] El Nemr A, Said TO, Khaled A, El-Sikaily A, Abd-Allah AMA. The distribution and sources of polycyclic aromatic hydrocarbons in surface sediments along the Egyptian Mediterranean coast. Environ. Monit. Assess. 2007; 124: 343-359.

[5] Harris KA, Yunker MB, Dangerfield N, Ross PS. Sediment-associated aliphatic and aromatic hydrocarbons in coastal British Columbia, Canada. Concentrations, composition and associated risks to protected sea otters, Environ. Pollut. 2011; 159: 2665-2674.

[6] Wu H, Sun B, Li J. Polycyclic aromatic hydrocarbons in sediments/soils of the rapidly urbanized lower reaches of the River Chaohu, China. Int. J. Environ. Res. Public Health. 2019; 16: 2302.

[7] Zhao Z, Qin Z, Cao J, Xia L. Source and ecological risk characteristics of PAHs in sediments from Qinhuai River and Xuanwu Lake, Nanjing, China. Hindawi Journal of Chemistry. 2017; Article ID: 3510796.

[8] Prabhukumar G, Pagilla K. Polycyclic aromatic hydrocarbons in urban runoff-sources, sinks and treatment: a review, Chicago: Du Page River Salt Creek Workgroup. 2010; 1-37.

[9] Brazkova M, Krastanov A. Polycyclic aromatic hydrocarbons: sources, effects and biodegradation. Hayxyb Tpylode Ha Pyceycrbz Eybdepcbnen. 2013; 52(2): 1-5.

[10] Sakuma T, Leigh D, Seto C, Schreiber A, Wittrig R. Analysis of polycyclic aromatic hydrocarbons (PAH), alkylated derivatives, and photo-degradation products in environmental and food samples using LCFLD-MS/MS with Q Technology. Food and environmental. 2011; 12: 1-3.

[11] El Nemr A, Moneer AA, Ragab S, El Sikaily A. Distribution and sources of n-alkanes and polycyclic aromatic hydrocarbons in Shellfish of the Egyptian Red Sea Coast. Egyptian Journal of Aquatic Research. 2016; 42: 121131.

[12] Wilson NK, Chuang JC, Lyu C. Levels of persistent organic pollutants in several child day care centers. Journal of Exposure Analysis and Environmental Epidemiology. 2001; 11: 449-458.

[13] Ordinioha B, Brisibe S. The human health implications of crude oil spills in the Niger Delta, Nigeria: An interpretation of published studies, Nigerian medical journal: journal of the Nigeria Medical Association. 2013; 54(1): 10.

[14] Gereslassie T, Workineh A, Liu X, Yan X, Wang J. Occurrence and ecological and human health risk assessment of polycyclic aromatic hydrocarbons in soils from Wuhan, central China, Int. J. Environ. Res. Public Health. 2018; 15: 2751.

[15] Fang GC, Huang JH, Huang YL. Polycyclic aromatic hydrocarbons in the Asian atmosphere during 2001 to 2009 , Environmental Forensics. 2010; 11: 207-215.

[16] Jamhari AA, Sahani M, Latif MT, Chan KM, Tan HS, Khan MF. Concentration and source identification of polycyclic aromatic hydrocarbons (PAHs) in PM10 of urban, industrial and semi-urban areas in Malaysia, Atmospheric Environment. 2014; 86: 16-24.

[17] Abdel-Shafy HI. A review on polycyclic aromatic hydrocarbons: source, environmental impact, effect on human health and remediation, Egyptian J. Petroleum. 2016; 25(1): 107-123.

[18] Adeyi AA, Oyeleke P. Heavy metals and polycyclic aromatic hydrocarbons in soil from E-waste dumpsites in Lagos and Ibadan, Nigeria. Journal of Health \& Pollution. 2017; 7: 15.

[19] Aigberua AO. Quantitative oil source fingerprinting and diagnostic ratios: application for the identification of soil residual hydrocarbon (SRH) in waste dump areas within oil well clusters. J. Environ. Treat. Tech. 2019; 7(2): 220228. 
[20] USEPA, Separatory funnel liquid-liquid extraction. United States Environmental Protection Agency (USEPA). Method 3510C. 2001.

[21] Aigberua AO. A survey of concentrations and source characterization of polycyclic aromatic hydrocarbons in surface waters of the Imiringi river system. International Research Journal of Pure \& Applied Chemistry. 2020; 21(10): 71-84.

[22] Yang Y, Woodward LA, Li QX, Wang J. Concentrations, source and risk assessment of polycyclic aromatic hydrocarbons in soils from midway Atoll, North Pacific Ocean. PLoS ONE. 2014; 9(1): e86441.

[23] USEPA, Provisional guidance for quantitative risk assessment of polycyclic aromatic hydrocarbons, United States Environmental Protection Agency (USEPA). Office of Health and Environmental Assessment. 1993.

[24] Jack DN, Abiye CM. Polycyclic Aromatic Hydrocarbons (PAHs) in surface water and their toxicological effects in some creeks of south east Rivers State (Niger Delta) Nigeria. IOSR Journal of Environmental Science, Toxicology and Food Technology. 2015; 9(12): 27-30.

[25] Rahel CB, Thomas DB, Thomas K, Jochen M, Franz XS, Joseph T. Fate of PCBs, PAHs and their source characteristic ratios during composting and digestion of source-separated organic waste in full-scale plants. Environmental Pollution. 2007; 148(2): 520-528.

[26] Zhi H, Zhao Z, Zhang L. The fate of polycyclic aromatic hydrocarbons (PAHs) and organochlorine pesticides (OCPs) in water from Poyang lake, the largest freshwater lake in China. Chemosphere. 2015; 119: 1134-1140. 